\title{
Value-conflict among adolescents: A study on locale differences
}

\author{
SAVITA RATHOUR AND TEJPREET K. KANG
}

Received: 30.09.2014; Revised: 05.03.2015; Accepted: 16.03.2015

See end of the paper for authors' affiliations SAVITA RATHOUR Department of Human Development, College of Home Science, Punjab Agricultural University, LUDHIANA (PUNJAB) INDIA

Email : savitarathour@yahoomail.com
-ABSTRACT : Values are listed as motivational factors that determine an individual's lifestyle, while the conflict is part of human life which is inevitable to avoid. Value-conflicts lie at the very root of an individual's identity, they are extremely difficult to resolve and descalation of the conflicts become an essential need for the welfare of mankind because they hold the seed of personality disorganization and inversely related to adjustment. Conflict regarding intrapersonal and interpersonal value preference starts occurring from late childhood, while it becomes more prominent among adolescents as they are more prone to various types of conflict. The present research has made an attempt to study value preferences and value-conflict among college students of Ludhiana district. The sample included 200 rural and 200 urban college students (400), in age range of 18-20 years. Value-conflict scale developed by Bharadwaj (2001) was used to measure value-conflict among adolescents. Result revealed that there was no significant difference in overall value conflict among rural and urban adolescents while, dimension wise there was significant difference in evasion vs fortitude, dependence vs self reliance and pragmatism vs idealism. On the basis of mean, in most of the dimensions respondents were in value conflict. Rural respondents had value conflict with a tendency towards evasion, dependence, selfishness and pragmatism while, urban respondents had value conflict with a tendency towards fortitude, self reliance, selfishness and fear. In hate vs love both rural and urban respondents had love value probability, in fear vs assertion rural respondents had fear value probability and in pragmatism and idealism urban respondents had pragmatism value probability.

KEY WORDS: Conflict, Values, Adolescents

- HOW TO CITE THIS PAPER : Rathour, Savita and Kang, Tejpreet K. (2015). Value-conflict among adolescents: A study on locale differences. Asian J. Home Sci., 10 (1) : 26-32. 